\title{
Analysis of Carbon Emission Efficiency for the Provinces of China
}

\author{
YU Dun-yong ${ }^{1}$ ZHANG Xue-hua ${ }^{1, * 2}$ \\ ${ }^{1}$ School of Economics, Tianjin Polytechnic University, Tianjin 300387 , \\ China; \\ Author Institute of Environmental Economics, Tianjin Polytechnic University, Tianjin 300387, China \\ Email: xuehua671231@163.com
}

\begin{abstract}
Keywords: Stochastic Frontier Analysis; Carbon Emission Efficiency; Production Factors; Difference
\end{abstract}

\begin{abstract}
Using the method of Stochastic Frontier Analysis (SFA), this paper chooses the rate of urbanization, the per capita Road area, the per capita green area, the green coverage rate, the third industrial proportion, the proportion of eight energy consuming industries, the intensity of the input into $R \& D$, environmental protection investment index, employees in the proportion of total population as the input factor, and GDP output of the unit carbon emission as the output factor to calculate and analyze the carbon emission efficiency of China's 30 provinces in 2006 and 2011. The results shows the carbon emission efficiency in Beijing, Hebei, Shanghai, Ningxia, and Xinjiang is decreased, while other provinces' shows the contrary result. Meanwhile there is a big difference between different regions.
\end{abstract}

\section{Introduction}

The Stochastic Frontier Analysis (SFA) was one of the more effective method of quantitative analysis, and the advantages of the quantitative analysis method were based on statistical data to establish the mathematical model, by using the mathematical model to calculate various index of the analysis object and their values. The carbon emission efficiency was not by intuitive feeling and experience, but using the data to establish model of calculation and analysis to analyze. Currently, many scholars used the Stochastic Frontier Analysis Method to carry on the carbon emission efficiency measurement and evaluation. Such as Chen Liming etal ${ }^{[1]}$ measured the carbon emission efficiency in each area of China from 1995 to 2009, studying the factors of affecting the carbon emission efficiency, and the results showed that the regional disparity had more influence on the carbon emission efficiency. Zhou Rui etal ${ }^{[2]}$ evaluated the carbon emission efficiency of the fifteen cities of Xinjiang from 2000 to 2011, which calculated the carbon emission efficiency for fifteen prefectures of Xinjiang from 2000 to 2011. According to the results of year 2011, the top three were Tacheng, Karamay, Bozhou, the bottom three were Kezhou, Shihezi, Hotan, and the average level was 0.614. Sun Hui etal ${ }^{[3]}$ selected 2003-2011 panel data to calculate the carbon emissions efficiency for west of China, according to the results, which classified the carbon emission efficiency of the west of China, and the carbon emissions efficiency was divided into high, middle and low efficiency zone. At the same time, there was huge potential for energy-saving and big upside for the west of China, which needed to be further studied the implementation of energy-saving and emission-mitigating measures to improve the carbon emissions efficiency.

The above used the Stochastic Frontier Method to provide the valuable reference for the study of the carbon emissions efficiency, but there were two common characteristics: firstly, the input factors and output factors were fixed; secondly, the selection was absolute quantity index, less consideration of regional differences, and the area and the economic scale of different regions were different, which often led to a great difference in the absolute amount of indicators between them. The comparability of indicators was poor, so it was difficult to objectively reflect the carbon emissions efficiency of a region. From the point of view of production factors, the paper selected 
nine relative quantity factors of inputs, and one output element is GDP of the unit carbon emission, which from different levels reflected differences of the regional investment.

\section{Model construction}

\subsection{Model introduction}

The Stochastic Frontier Production Function Method was respectively proposed by Aigner, Lover, Schimidt $^{[4]}$, Meeusen and Van den Broeck ${ }^{[5]}$ in 1997. The function biggest characteristic was to consider the influence of random factors on output. At the same time, it could study the panel data of across the period, to make research results more close to reality. The basic structure of the Stochastic Frontier Model is as follows :

$$
y_{i t}=x_{i t} \beta+\left(v_{i t}-u_{i t}\right), \quad i=1,2, \cdots, N
$$

The upper type $y_{\text {it }}$ was the ith individual in the $t$ th year's output or output logarithm, $x_{\text {it }}$ as the explained variable vector, which meant the ith individual in the th year's input or input logarithm, which $\beta$ was the parameter vector to be estimated. $v_{i t}$ indicated the random error term, subjecting to $(0,2)$, and $\boldsymbol{u}_{i t}$ indicated as a technical inefficiency of nonnegative.

\subsection{Model construction}

\subsubsection{Indicators selection}

Traditional production input factors including land, capital and labor, with the progress of science and technology, resource environment for economic development constraints tightening, scientific and technological innovation and environmental protection investment to the impact of carbon efficiency was becoming more and more significant. In view of the above, this paper selected the urbanization rate $(U)$, the per capita road area $(R)$, the per capita green area $(G)$, the green coverage rate $(C)$, the proportion of the third industry $(S)$, the proportion of eight energy consuming industries $(E)$, the intensity of the input into $R \& D(D)$, environmental protection investment index $(I)$, employees in the proportion of the total population $(L)$ etc, nine relative quantity index as input index. The selection and design of output indicators were relatively simple, that is, GDP of the unit carbon emission.

\subsubsection{Model structure}

The basic structure of the Stochastic Frontier Model of the carbon emission efficiency evaluation is as follows :

$$
\begin{aligned}
\ln y_{i t}= & \beta_{0}+\sum_{n=1}^{9} \beta_{n} \ln x_{n i t}+\frac{1}{2} \sum_{n=1}^{9} \sum_{j=1}^{9} \beta_{n j} \ln x_{n i t} \ln x_{j i t} \\
& +\frac{1}{2} \sum_{n=j=1}^{9} \beta_{n j}\left(\ln x_{n i t}\right)^{2}+v_{i t}-u_{i t}
\end{aligned}
$$

$x_{1}, \cdots, x_{9}$ of (2) type successively represented $U, R, G, C, S, E, D, I, L \cdot y_{i t}$ was carbon emission efficiency, which was defined as the ratio of the expected value of per unit $\mathrm{CO}_{2}$ actual output to the output expectation of production frontier boundary, namely :

$$
T E_{i t}=\frac{E\left[y_{i t}\right]}{E\left[y_{i t} / u_{i t}=0\right]}=\exp \left(-u_{i t}\right)
$$

By the formula of the definition of the carbon emission efficiency knowing, the carbon emission efficiency value of the formula (3) was between 0 and 1 . If the efficiency was high, the value was close to 1, which would mean that the production of the Stochastic Frontier was more effective; equal to 1, indicating that the production technology of the Stochastic Frontier had been fully played, so for the Sochastic Frontier production efficiency was higher, the better. 


\section{Empirical analysis}

\subsection{Data source}

This paper selected 2006, 2011 data of 30 provinces as statistical samples, and the required data were collected from the energy statistics yearbook of various provinces and cities, as well as the statistical yearbook of various provinces and cities and "China Energy Statistical Yearbook", "China Environmental Statistics Yearbook" (2007, 2012). Including gasoline, crude oil, kerosene, fuel oil, diesel oil, raw coal, coke, oil field gas, refinery dry gas, liquefied petroleum gas 10 kinds of final energy consumption, which were eventually converted into $\mathrm{CO}_{2}$ emissions, and all of the data were carried out dimensionless processing. By conversion coefficient of various energy carbon emissions to convert. The basic information of the conversion coefficient of various energy carbon emissions was as table 1 (data source: China contract energy management network).

Table.1 Conversion coefficient of various energy carbon emissions

\begin{tabular}{llll}
\hline \multicolumn{1}{c}{ Energy } & $\begin{array}{c}\text { The averge net } \\
\text { calorific value }\end{array}$ & $\begin{array}{c}\text { Converted to } \\
\text { standard coal cofficient }\end{array}$ & $\begin{array}{c}\text { Carbon dioxide emission } \\
\text { cofficient }\end{array}$ \\
\hline Gasoline & $43070 \mathrm{~kJ} / \mathrm{kg}$ & $1.4714 \mathrm{kgce} / \mathrm{kg}$ & $2.9251 \mathrm{~kg}-\mathrm{CO}_{2} / \mathrm{kg}$ \\
Crude oil & $41816 \mathrm{~kJ} / \mathrm{kg}$ & $1.4286 \mathrm{kgce} / \mathrm{kg}$ & $3.0202 \mathrm{~kg}-\mathrm{CO}_{2} / \mathrm{kg}$ \\
Kerosene & $43070 \mathrm{~kJ} / \mathrm{kg}$ & $1.4714 \mathrm{kgce} / \mathrm{kg}$ & $3.0179 \mathrm{~kg}-\mathrm{CO}_{2} / \mathrm{kg}$ \\
Fuel oil & $41816 \mathrm{~kJ} / \mathrm{kg}$ & $1.4286 \mathrm{kgce} / \mathrm{kg}$ & $3.1705 \mathrm{~kg}-\mathrm{CO}_{2} / \mathrm{kg}$ \\
Diesel oil & $42652 \mathrm{~kJ} / \mathrm{kg}$ & $1.4571 \mathrm{kgce} / \mathrm{kg}$ & $3.0959 \mathrm{~kg}-\mathrm{CO}_{2} / \mathrm{kg}$ \\
Raw coal & $20908 \mathrm{~kJ} / \mathrm{kg}$ & $0.7143 \mathrm{kgce} / \mathrm{kg}$ & $1.9003 \mathrm{~kg}-\mathrm{CO}_{2} / \mathrm{kg}$ \\
Coke & $28435 \mathrm{~kJ} / \mathrm{kg}$ & $0.9714 \mathrm{kgce} / \mathrm{kg}$ & $2.8604 \mathrm{~kg}-\mathrm{CO}_{2} / \mathrm{kg}$ \\
Oil field gas & $38931 \mathrm{~kJ} / \mathrm{m} 3$ & $1.3300 \mathrm{kgce} / \mathrm{m}^{3}$ & $2.1622 \mathrm{~kg}-\mathrm{CO}_{2} / \mathrm{m}^{3}$ \\
Refinery-dry & $46055 \mathrm{~kJ} / \mathrm{kg}$ & $1.5714 \mathrm{kgce} / \mathrm{kg}$ & $3.0119 \mathrm{~kg}-\mathrm{CO}_{2} / \mathrm{kg}$ \\
\multicolumn{1}{c}{ gas } & & & \\
Liquefied & $50179 \mathrm{~kJ} / \mathrm{kg}$ & $1.7143 \mathrm{kgce} / \mathrm{kg}$ & $3.1013 \mathrm{~kg}-\mathrm{CO}_{2} / \mathrm{kg}$ \\
petroleum gas & & &
\end{tabular}

The UN's Intergovernmental Panel on Climate Change (IPCC) 2006 proposed a carbon emissions calculation guide. The calculation formula is as follows :

$$
C \mathrm{O}_{2}=\sum_{i=1}^{n} E_{i} \times C_{i}
$$

$\mathrm{CO}_{2}$ as the carbon emissions of the energy consumption, $E_{i}$ as the energy consumption of the ith, $C_{i}$ as the energy carbon emission coefficient of the $i$ th, the $i$ was energy type.

\subsection{Calculation results}

This paper used the Stochastic Frontier Model, making use of the Frontier 4.1 software to calculate the panel data of 30 provinces in 2006 and 2011, getting the carbon emission efficiency of 30 provinces. The estimation results of the parameters could be obtained by the software, excluding the results of the non sensitive inputs, as shown in Table 2, which the carbon emission efficiency was shown in Table 3. 
Table.2. Estimation results of 30 provinces stochastic frontier parameters in 2006 and 2011

\begin{tabular}{llll}
\hline Variables & $\begin{array}{c}\text { Coefficient } \\
\text { (Significance) }\end{array}$ & Variables & $\begin{array}{c}\text { Coefficient } \\
\text { (Significance) }\end{array}$ \\
\hline$\beta_{0}$ & $7.8449(3.6067)$ & $\beta_{7}$ & $2.8149(7.006)$ \\
$\beta_{1}$ & $0.4459(3.6885)$ & $\beta_{8}$ & $-12.5594(-4.4976)$ \\
$\beta_{4}$ & $0.9490(3.4534)$ & $\beta_{9}$ & $0.3382(4.976)$ \\
$\beta_{5}$ & $-0.0279(-4.01)$ & $\sigma^{2}$ & 0.0152 \\
$\beta_{6}$ & $-0.0279(-3.635)$ & $\gamma$ & 0.8371 \\
Logarithmic function value $=45.9265$ & &
\end{tabular}

Note: $t$ value was within the brackets, and all coefficients rejected null hypothesis under the $1 \%$ significant level.

As could be seen from the table $2, \gamma$ was significantly under the $1 \%$ significant level, which rejected the null hypothesis, and $\gamma$ 's value was 0.8371 , which indicated that the paper adopting the analysis method of the Stochastic Frontier Production Model was reasonable.

Table.3 Carbon emission efficiency of 30 provinces in 2006 and 2011

\begin{tabular}{cccccc}
\hline Regions & 2006 & 2011 & Regions & 2006 & 2011 \\
\hline Beijing & $\mathbf{0 . 9 7 9 8}$ & $\mathbf{0 . 9 7 9}$ & Henan & 0.9306 & 0.9452 \\
Tianjin & 0.9686 & 0.9705 & Hubei & 0.9431 & 0.9477 \\
Hebei & $\mathbf{0 . 9 2 5 6}$ & $\mathbf{0 . 9 0 7}$ & Hunan & 0.9367 & 0.9501 \\
Shanxi & 0.9128 & 0.9201 & Guangdong & 0.967 & 0.9672 \\
Inner & 0.8343 & 0.9006 & Guangxi & 0.924 & 0.9331 \\
Mongolia & & & & & \\
Liaoning & 0.9477 & 0.9534 & Hainan & 0.9531 & 0.9616 \\
Jilin & 0.9406 & 0.946 & Chongqing & 0.8648 & 0.9347 \\
Heilongjiang & 0.9462 & 0.9498 & Sichuan & 0.927 & 0.9473 \\
Shanghai & $\mathbf{0 . 9 7 6 6}$ & $\mathbf{0 . 9 7 3 9}$ & Guizhou & 0.8613 & 0.9005 \\
Jiangsu & 0.963 & 0.9763 & Yunnan & 0.8738 & 0.9224 \\
Zhejiang & 0.9654 & 0.9672 & Shaanxi & 0.9395 & 0.9531 \\
Anhui & 0.9292 & 0.9384 & Gansu & 0.8577 & 0.8747 \\
Fujian & 0.9561 & 0.9699 & Qinghai & 0.8876 & 0.8954 \\
Jiangxi & 0.9405 & 0.9436 & Ningxia & $\mathbf{1}$ & $\mathbf{0 . 8 7 3 5}$ \\
Shandong & 0.9512 & 0.9571 & Xinjiang & $\mathbf{0 . 9 2 2 6}$ & $\mathbf{0 . 9 0 4 5}$ \\
& Mean values of 30 provinces & & 0.9388 & 0.9349 \\
\hline
\end{tabular}




\subsection{Results analysis}

The calculation results of the carbon emission efficiency and the carbon emission efficiency of 30 provinces in 2011 and 2006 were as shown in table 3. The table marked the provinces of the carbon emission efficiency decline in 2006 and 2011, which were Beijing, Hebei, Shanghai, Ningxia, Xinjiang. The largest decline of the carbon emission efficiency was Ningxia in five provinces, from 1 to 0.8735 , which felled by 0.1265 ; followed by Hebei, which felled by 0.0181 ; in turn, Xinjiang felled by 0.0186, Shanghai felled by 0.0027, and Beijing felled by 0.0008 . Although this five provincial carbon emission efficiency had fallen, Beijing, Shanghai's carbon emissions efficiency were higher than the average level of 30 provinces in 2006 and 2011. Ningxia's carbon emissions efficiency was 1 in 2006, but quickly dropped to 0.8735 in 2011, lower than the average level. Hebei, Xinjiang's had a certain gap compared with the average.

In addition to the above five provinces, other provinces' carbon emission efficiency was showing a rising trend. Chongqing, which was the largest increase, rose by 0.0699 from 2006 to 2011 . Followed by Inner Mongolia, which rose by 0.0663 , Henan rose by 0.0146 , Fujian rose by 0.0138 , Hunan rose by 0.0663 , and Jiangsu rose by 0.0133 . In addition, there were more than ten provinces' carbon emission efficiency whose was lower than the average level of 30 provinces in 2006 and 2011. Large differences between different provinces, the magnitude of the rise presented a different trend.

As shown figure 1 was the carbon emission efficiency of four municipalities. The figure 1 showed that Beijing's carbon emission efficiency had been at the top of the four municipalities in 2006 and 2011. Compared with Beijing's and Shanghai's, it could be seen that the carbon emission efficiency of Tianjin was slightly lower than that of Beijing and Shanghai, living in third, and its carbon emission efficiency increase was relatively slow, just faster than Beijing's, behind Chongqing's and Shanghai's. The sharpest rise in Chongqing, was 0.0669, but its carbon emission efficiency was significantly lower than the other three municipalities, and the carbon emission efficiency in 2006 and 2011 was less than the average level of the 30 provinces, which indicated that Chongqing needed to further improve the carbon emission efficiency.

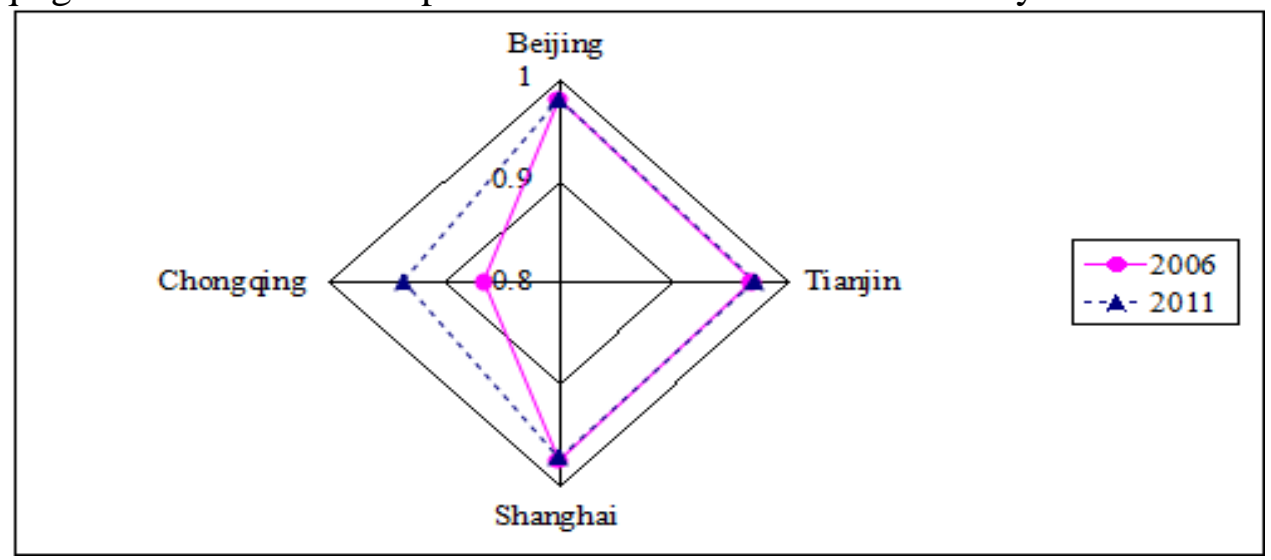

Figure.1 Carbon emission efficiency of four municipalities in 2006 and 2011

\section{Conclusion}

On the base of the Stochastic Frontier Analysis, this paper calculated and analyzed the carbon emission efficiency of China's 30 provinces in 2006 and 2011. By analyzing, we got the following conclusions: in 2006 and 2011, the carbon emission efficiency of the most provinces was increased except Beijing, Hebei, Shanghai, Ningxia and Xinjiang. There was a huge gap between the different regions, but there was room for improvement. According to the above analysis, we made some policy recommendations :

For the low and falling regions of the carbon emission efficiency, it was necessary to speed up high energy consuming industries transformation, reduce $\mathrm{CO}_{2}$ emissions, strictly control of pollution and emission link, and improve the efficiency of production technology, While maintaining the original economic benefits to reduce carbon emissions. 
For the rising regions of the carbon emission efficiency, it must be further improved on the basis of maintaining current levels. It must focus on the improvement of economic quality, develop the low-carbon economy and ecological economy, innovate management and update equipment to develop new and high technology industry to create a better atmosphere for the development.

All in all, by analyzing, we could find that our country energy saving and emission reduction should be according to the difference of the different provinces' carbon emission efficiency to implement measures to local conditions. Only did this, could every province better utilize their energy saving and emission reduction potentials to develop the low-carbon economy, coordinate the development of the economy, society and the environment, and ultimately improve the level of the carbon emission efficiency.

\section{Acknowledgements}

This work was supported by National Social Science Fund Project "Full Carbon Efficiency Measurement and Evaluation of Ecological Economic Area (12BJY025)"

\section{References}

[1] Chen Liming, Huang Wei. Analysis of Carbon Emission Efficiency for the Provinces of China Based on Stochastic Frontier[J]. Statistics and Decision, 2013 (9): 136-139.

[2] Zhou Rui, Sun Hui, Zhang Zhiqiang. Evaluation of carbon emission efficiency of the fifteen prefectures of Xinjiang based on Stochastic Frontier Model[J]. Journal of Xinjiang University, 2014, 31 (3): 369-373.

[3] Sun Hui, Zhao Zhiqiang, Zhou Rui. Evaluation studies of the Carbon Emission Efficiency of the Western of China based on Stochastic Frontier Model[J]. Industrial Technology Economy, 2012 (12): 71-77.

[4] Aigner,D.J.,C.A.K Lovell,and Schmidt.Formula-tion and Estimation of Stochastic Frontier Production Functions Models[J]. Journal of Econometrics, 1977,6:1 (7): 21-37.

[5] Meeusen.W.,\&J.van den Broeck.Efficiency Esti-mation from Cobb-Douglas Production Functions with Composed Error[J]. International Economic Review,1977,18:2 (6): 435-444. 